\title{
KINERJA SIMPANG EMPAT TAK BERSINYAL CIKOLE LINTAS TIMUR KABUPATEN PANDEGLANG
}

\author{
Nila Prasetyo Artiwi ${ }^{1}$, Telly Rosdiyani ${ }^{2}$ Hidayatullah $^{3}$ \\ ${ }^{1,2,3}$ Program Studi Teknik Sipil, Universitas Banten Jaya, Jl. Raya Ciwaru II No. 73 Kota Serang, Banten \\ Email: prasetyonila2@gmail.com \\ Email: tellyrosdiyani004@gmail.com \\ Email: hidayatullah2292@gmail.com
}

\begin{abstract}
ABSTRAK
Simpang merupakan prasarana jalan yang penting. Permasalahan lalu lintas seperti kecelakaan dan kemacetan umumnya terjadi di simpang, hal ini dikarenakan simpang merupakan pertemuan beberapa ruas jalan dan titik konflik berbagai pengguna jalan. Oleh karena itu perlu dilakukan penelitian pada simpang dengan tujuan untuk mengatasi permasalahan yang terjadi, terutama yang berkaitan dengan kondisi operasional. Penelitian ini dilakukan pada simpang empat tak bersinyal Cikole dengan pengamatan selama 3 hari, yaitu Senin 20 Januari 2020, Kamis 23 Jnauari 2020 dan Minggu 26 Januar 2020, pengumpulan data lalu lintas yang dilakukan 3 periode yaitu pagi (06:00-08:00), siang (11:00-13:00) dan sore (16:00-18:00). Pengambilan data lalu lintas dilakukan dengan mencatat jumlah kendaraan yang melewati simpang tiap 15 menit selama $2 \mathrm{jam}$. Dari hasil pengumpulan data diperoleh data primer berupa kondisi geometrik, data lalu lintas, kondisi lingkungan dan data sekunder berupa data jumlah penduduk. Analisis dilakukan berdasarkan Manual Kapasitas Jalan Indonesia (MKJI) 1997. Dari hasil analisis disimpang tak bersinya diperoleh derajat kejenuhan (DS) 0,70 menunjukkan bahwa memenuhi persyaratan MKJI 1997. setelah dilakukan analisis ke perancangan bersinyal menunjukan derajat kejenuhan mengalami kenaikan yaitu sebesar 0,90 .
\end{abstract}

Kata Kunci: Simpang Cikole, MKJI 1997, Derajat Kejenuhan, Perancangan Sinyal

\begin{abstract}
The intersection is important road infrastructure. Traffic problems such as accidents and congestion generally occur at intersections, this is because the intersection is a meeting of several roads and conflict points of various road users. Therefore it is necessary to conduct research at the intersection with the aim to overcome the problems that occur, especially those related to operational conditions. This research was conducted at the Cikole unsigned four-way intersection with observations for 3 days, namely Monday 20 January 2020, Thursday 23 January 2020 and Sunday 26 January 2020, traffic data collection was carried out in 3 periods namely morning (06: 00-08: 00), afternoon (11: 00-13: 00) and afternoon (16: 00-18: 00). Traffic data collection is done by recording the number of vehicles that cross the intersection every 15 minutes for 2 hours. The results of data collection obtained primary data in the form of geometric conditions, traffic data, environmental conditions, and secondary data in the form of population data. The analysis was carried out based on the 1997 Indonesian Road Capacity Manual (MKJI). The results of the unsignalized analysis obtained a degree of saturation (DS) of 0.70 indicating that it met the 1997 MKJI requirements. After an analysis of the signaling design showed the degree of saturation had increased by 0.90 .
\end{abstract}

Keywords: Cikole Intersection, MKJI 1997, Degree of Saturation, Signal Design 


\section{PENDAHULUAN}

Menurut Hamirhan Saodang (2010) persimpangan adalah titik simpul dalam jaringan transportasi dimana dua atau lebih ruas jalan bertemu. Pertemuan arus lalu lintas sering terjadi konflik lalu lintas. Dalam mengendalikan konflik ini sudah ada beberapa solusi yang datang untuk dalam mengatur pergerakan arus lalu lintas di simpang Cikole. Simpang Cikole terdapat diruas jalan ABRI Masuk Desa (AMD) Lintas Timur Kabupaten Pandeglang yang menghubungkan ruas berbagai pusat kegiatan masyarakat, ditengah arus lalu lintas dengan pola pergerakan kebutuhan dalam pendidikan, tempat kerja, sarana perdagangan, serta tempat wisata.

Salah satu penelitian Wahyudin dkk (2015) yang menganalisis kinerja simpang tak bersinyal jalan pakuningratan, menghitung volume kendaraan yang melewati persimpangan tersebut berdasarkan parameter Manual Kapasitas Jalan Indonesia (1997) didapat hasil kondisi eksisiting pada simpang menunjukkan kinerja kurang baik. Dengan pemecahan masalah alternatif maka dilakukannya pemberlakuan jalan satu arah lengan barat jalan pakuningratan.

Bedasarkan hasil obeservasi pada salah satu simpang yang terdapat pada ruas jalan Provinsi memiliki tipe 2 lajur tanpa median jalan dengan lebar masing-masing bagian simpang yaitu penghubung jalan Majasari-Cibiuk 4,5 meter sedangkan ruas jalan Serang-Labuan 6,5 meter dengan kondisi sekitar simpang terdapat halte bis dan juga pertokoan yang tidak memiliki bahu jalan untuk parkir. Hal tersebut dikhawatirkan akan terjadinya hambatan samping yang menyebabkan terjadinya kemacetan. Dengan bertambahnya jumlah penduduk setiap tahunnya tentu kondisi ini sudah berpengaruh terhadap aktivitas masyarakat yang menyebabkan dampak kinerja ruas jalan dapat berpengaruh terhadap kapasitas maupun tundaan yang berdampak rumit. Permasalahan tundaan dan antrian simpang yang sering terjadi di sekitar Cikole ini dikarenakan bertambahnya volume kendaraan yang tanpa di imbangi oleh sarana transportasi yang memadai. Berdasarkan uraian diatas maka peneliti perlu melakukan penelitian dengan judul "Kinerja Simpang Empat Tak Bersinyal Cikole Lintas Timur Kabupaten Pandeglang".

\section{Rumusan Masalah}

Bagaimana karakteristik lalu lintas disimpang empat tak bersinyal Cikole?

Bagaimana kinerja simpang empat tak bersinyal cikole pada kondisi eksisting?

Berapa waktu fase yang dibutuhkan pada masing-masing lengan simpang Cikole?

\section{Tujuan Penelitian}

Mengetahui karakteristik lalu lintas kondisi dilapangan

Menganalisis kinerja simpang empat tak bersinyal Cikole Kabupaten Pandeglang pada kondisi eksisting

Memperoleh alternative perancangan pengaturan sinyal untuk meningkatkan kinerja simpang empat tak bersinyal Cikole Kabupaten Pandeglang

\section{METODOLOGI PENELITIAN}

Dalam penelitan ini ada beberapa tahapan yang harus dilakukan : tahap persiapan, adalah survey kelokasi untuk mencari permasalahan setelah itu lanjut melakukan studi literatul tentang penelitian yang sejenis, tahapan pengambilan data, berupa data primer berupa survey kelokasi sedangkan data sekunder diperoleh dari buku atau instansi terkait, tahap analisa, menggunakan metode Manual Kapasitas Jalan Indonesia (MKJI) 1997.

Tahapan penelitian berupa data arus lalulintas pada simpang cikole yang dihitung terdiri dari kendaraan ringan (light vehicle), kendaraan berat (height vehicle), sepeda motor (motorcycle) dari ketiga jenis kendaraan tersebut masing-masing dibagi menjadi belok kiri, lurus dan belok kanan. dengan mengamati langsung dilokasi simpang

Jenis data pada penelitian ini dibagi menjadi dua bagian yaitu: Data Primer, didapatkan dari hasil pengamatan berupa data arus lalulintas, kondisi geometrik, kondisi lingkungan, dan hambatang samping. Data Sekunder, data tertulis yang diperoleh lewat pihak terkait, tidak langsung diperoleh peneliti dari subjek penelitiannya, data ini juga sebagai landasan permasalahan yang ada sekaligus pembanding keadaan saat ini. melainkan melalui sumber lain, baik lisan maupun tertulis. 
Jenis data yang akan di masukkan ke olah data yaitu : hasil survei geometrik, Dengan cara mengukur lebar lengan, lebar pendekat, kondisi lingkungan, hambatan samping,fasilitas jalan dan rambu-rambu lalu lintas yang terdapat pada simpang Cikole. Survey data arus lalu - lintas, berupa pengamatan langsung dilapangan dengan waktu pagi hari $06.00-08.00 \mathrm{WIB}$, siang $11.00-13.00 \mathrm{WIB}$, dan sore $16.00-18.00 \mathrm{WIB}$.

Lokasi penelitian, untuk pengambilan volume kendaraan dilakukan lamanya tiga hari pada hari kerja yaitu Senin dan kamis sedangkan untuk hari Minggu yaitu hari libur. Penelitian ini berlokasi di simpang empat Cikole merupakan Jalan. AMD Lintas Timur yang mempertemukan: Pendekat A= Jalan Majasari, Pendekat $\mathrm{C}=$ Jalan Cibiuk, Pendekat B= Jalan Serang, dan pendekat $\mathrm{D}=$ Jalan Labuan

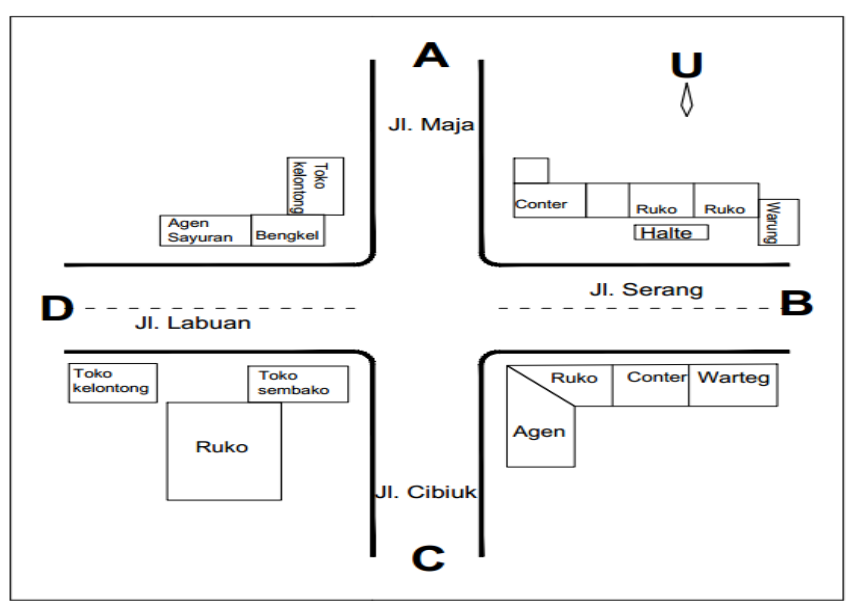

Gambar 1 Peta Titik Survey dan Lokasi Surveyor Sumber: Hasil Pengamatan

Untuk menganalisa dimasukan data primer yang diperoleh dari hasil dilapangan digunakan sebagai bahan yang akan dihitung dengan berpedoman pada Manual Kapasitas Jalan Indonesia, 1997. Proses dilakukan untuk mengetahui kinerja dari masing-masing pendekat ataupun lengan pada simpang tak bersinyal yang akan ditinjau seperti arus jenus, kapasitas, derajat kejenuhan, waktu siklus, panjang antrian, rasio kendaraan terhenti, dan tundaan. Dari hasil hitungan tersebut maka akan diketahui tingkat pelayaann (level of service) saat ini. Berikut ada dua analisis yang menjadi tujuan penelitian. Analisis Kinerja Eksisting, data sibuk atau jam puncak yang dikumpulkan dilapangan dilakukan selam enam jam. Untuk keperluan perhitungan digunakan data yang memliki jam puncak tertingi diantara periode dari rentang jam tersebut. Pada perhitungan analisi simpang ini digunakan metode Manual Kapasitas Jalan Indonesia 1997 untuk menentukan prliaku lalu lintas. Pemasangan Sinyal pada simpang tersebut dari kondisi eksisting yang sebelumnya simpang tersebut tidak bersinyal. Dari data yang telah didapat dari survey penggunaan analisis simpang bersinyal hanya digunakan pada jam puncak saja. Selain data jam puncak yang dimasukkan, terdapat variabel lain yang dimasukkan dalam analisi seperti lebar jalan, hambatan sampng, faktor penyesuaian, dan lain-lain.

\section{DATA DAN ANALISA}

Data yang diperoleh untuk proses analisis dalam penelitian ini terdiri dari data primer data sekunder. Data primer merupakan data yang diperoleh observasi atau pengamatan langsung dari lapangan sedangkan data sekunder diperoleh dari literatur ataupun informasi dari instansi-instansi terkait. Data sekunder dalam penelitian ini berfungsi sebagai data pendukung dari data primer.

\subsection{Hasil Pengumpulan Data Primer}

\subsubsection{Data Geometrik}

Pengamatan pada saat survei menemukan bahwa simpang Cikole merupakan pertemuan jalan Serang - Labuan sebagai jalan utama dan jalan Maja - Cibiuk sebagai jalan minor. Simpang ini memliki 4 buah lengan dan setiap lengan memiliki 2 lajur. Lebar pada jalan utama adalah 6,5 m sedangkan pada jalan minor adalah 4,5 $\mathrm{m}$. Data hasil pengamatan dan pengukuran lapangan dapat dilihat pada Gambar 4.1 berikut. 
Gambar 2 Geometrik Simpang Cikole

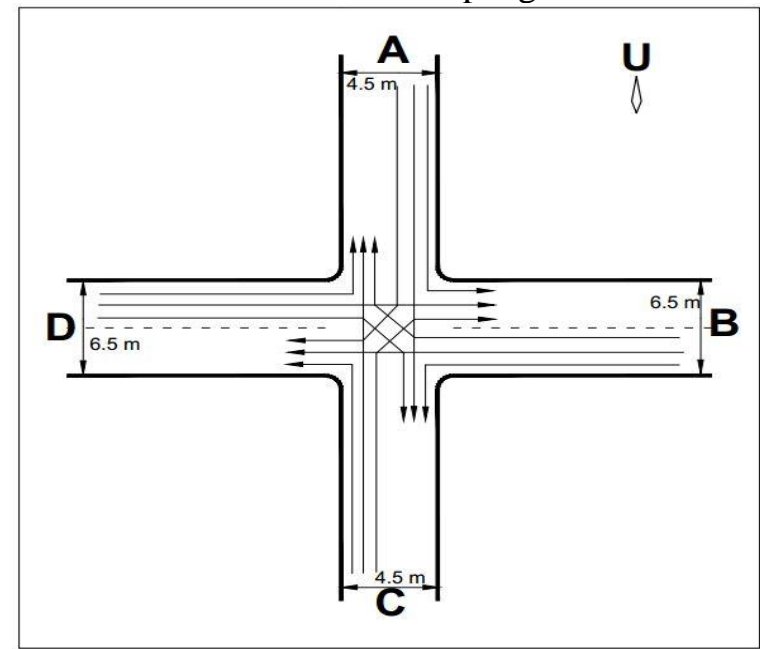

Sumber: Penelitian 2020

\subsubsection{Kondisi Lingkungan}

Berdasarkan pengamatan pada simpang Cikole untuk tipe lingkungan jalan berada pada kawasan perdagangan, hal ini dapat dilihat dari bangunan yang berdiri sebagian besar iyalah toko - toko permanen seperti toko agen sembako, warung makan, counter, dan toko pakaian, sepatu dan tas. Dengan median jalan utama Cikole tanpa median.

Tabel 1 Data Geometrik Kondisi Lingkungan Simpang Cikole

\begin{tabular}{lcccc}
\hline Tipe Pendekat & $\begin{array}{c}\text { Jl. Majasari } \\
(\mathrm{A})\end{array}$ & $\begin{array}{c}\text { Jl. Cibiuk } \\
(\mathrm{C})\end{array}$ & $\begin{array}{c}\text { Jl. Serang } \\
(\mathrm{B})\end{array}$ & $\begin{array}{c}\text { Jl. Labuan } \\
(\mathrm{D})\end{array}$ \\
\hline Tipe Lingkungan & $\mathrm{COM}$ & $\mathrm{COM}$ & $\mathrm{COM}$ & $\mathrm{COM}$ \\
Median & - & - & - & - \\
Lebar Pendekat $(\mathrm{m})$ & 4,5 & 4,5 & 6,5 & 6,5 \\
\hline
\end{tabular}

\subsubsection{Kondisi Lalu Lintas}

Survei untuk pengambilan data arus lalu lintas dilakukan dengan pengamatan langsung dilapangan dengan alat bantu aplikasi counter selama 2 jam dengan durasi 15 menit dari pagi jam 06.00 sampai 08.00 WIB, siang jam 11.00 sampai $13.00 \mathrm{WIB}$, dan sore hari 16.00 sampai 18.00 WIB. hari kerja yaitu Senin 20 Januari 2020, Kamis 23 Januari 2020, sedangkan pada hari libur yaitu Minggu 26 Januari 2020. Data arus lalu lintas didapat dari jumlah jam puncak kendaraan yang melewati simpang Cikole, hari Minggu.

Tabel 2 Rekapitulasi Data Tiap Pendekat Hari Minggu

\begin{tabular}{cccccc}
\hline \multirow{2}{*}{ Waktu } & \multicolumn{5}{c}{ Data Lalu Lintas Tiap Pendekat } \\
\cline { 2 - 6 } & $\begin{array}{c}\text { Jl. Majasari } \\
(\mathrm{A})\end{array}$ & $\begin{array}{c}\text { Jl. Cibiuk } \\
(\mathrm{C})\end{array}$ & $\begin{array}{c}\text { Jl. Serang } \\
(\mathrm{B})\end{array}$ & $\begin{array}{c}\text { Jl. Labuan } \\
(\mathrm{D})\end{array}$ & Total \\
\hline 06:00 - 07:00 & 661 & 593 & 809 & 909 & 2972 \\
07:00 - 08:00 & 759 & 770 & 1104 & 1217 & 3850 \\
11:00 - 12:00 & 721 & 715 & 1321 & 1264 & 4021 \\
12:00 - 13:00 & 800 & 792 & 1466 & 1273 & 4331 \\
16:00 - 17:00 & 744 & 810 & 994 & 1083 & 3631 \\
17:00 - 18:00 & 584 & 627 & 770 & 736 & 2717 \\
\hline
\end{tabular}

untuk memasukan data tiap pendekat pada hari Minggu dengan jam 12:00-13:00 ke formulir USIG-I data arus lalu lintas tersebut kemudian dikonversi kesatuan mobil penumpang (smp/ jam). dapat dilihat pada Tabel 3 berikut. 
Tabel 3 USIG-I Hasil Perhitungan Arus Lalu Lintas Rasio Berbelok Simpang Tak Bersinyal

\begin{tabular}{|c|c|c|c|c|c|c|c|c|c|}
\hline \multirow{3}{*}{$\begin{array}{c}\text { Kode } \\
\text { Pendekat }\end{array}$} & \multirow{3}{*}{ Arah } & \multicolumn{8}{|c|}{ Volume Kendaraan } \\
\hline & & \multicolumn{2}{|c|}{ LV } & \multicolumn{2}{|c|}{$\mathrm{HV}$} & \multicolumn{2}{|c|}{$\mathrm{MC}$} & \multirow{2}{*}{$\begin{array}{c}\begin{array}{c}\text { Kendaraan } \\
\text { Total }\end{array} \\
\text { smp/jam }\end{array}$} & \multirow{2}{*}{$\begin{array}{c}\text { Rasio } \\
\text { Berbelok }\end{array}$} \\
\hline & & kend/jam & $\begin{array}{l}\text { emp }=1,0 \\
\text { smp/jam }\end{array}$ & kend/jam & $\begin{array}{l}\text { emp }=1,3 \\
\text { smp/jam }\end{array}$ & kend/jam & $\begin{array}{l}\text { emp }=0,5 \\
\text { smp/jam }\end{array}$ & & \\
\hline \multirow{4}{*}{$\begin{array}{c}\text { Minor. A } \\
\text { (Majasari) }\end{array}$} & LT & 42 & 42 & 19 & 25 & 211 & 106 & 172 & 0,33 \\
\hline & ST & 47 & 47 & 32 & 42 & 204 & 102 & 191 & \\
\hline & RT & 43 & 43 & 21 & 27 & 174 & 87 & 157 & 0,30 \\
\hline & Total & 132 & 132 & 72 & 94 & 589 & 295 & 520 & \\
\hline \multirow{4}{*}{$\begin{array}{l}\text { Minor. C } \\
\text { (Cibiuk) }\end{array}$} & LT & 42 & 42 & 18 & 23 & 183 & 92 & 157 & 0,30 \\
\hline & ST & 41 & 41 & 32 & 42 & 202 & 101 & 184 & \\
\hline & RT & 42 & 42 & 20 & 26 & 225 & 113 & 181 & 0,34 \\
\hline & Total & 125 & 125 & 70 & 91 & 610 & 305 & 521 & \\
\hline \multicolumn{2}{|c|}{ Jl. Minor A+C } & 257 & 257 & 142 & 185 & 1199 & 600 & 1041 & \\
\hline \multirow{4}{*}{$\begin{array}{c}\text { Utama. B } \\
\text { (Serang) }\end{array}$} & LT & 45 & 45 & 25 & 33 & 186 & 93 & 171 & 0,17 \\
\hline & ST & 236 & 236 & 65 & 85 & 643 & 322 & 642 & \\
\hline & RT & 45 & 45 & 21 & 27 & 192 & 96 & 168 & 0,17 \\
\hline & Total & 326 & 326 & 111 & 144 & 1021 & 511 & 981 & \\
\hline \multirow{4}{*}{$\begin{array}{c}\text { Utama. D } \\
\text { (Labuan) }\end{array}$} & LT & 45 & 45 & 24 & 31 & 192 & 96 & 172 & 0,20 \\
\hline & ST & 208 & 208 & 41 & 53 & 501 & 251 & 512 & \\
\hline & RT & 46 & 46 & 24 & 31 & 187 & 94 & 171 & 0,20 \\
\hline & Total & 299 & 299 & 89 & 116 & 880 & 440 & 855 & \\
\hline \multicolumn{2}{|c|}{ Jl. Utama B+D } & 625 & 625 & 200 & 260 & 1901 & 951 & 1836 & \\
\hline \multirow{3}{*}{$\begin{array}{l}\text { Utama + } \\
\text { Minor }\end{array}$} & LT & 174 & 174 & 86 & 112 & 772 & 386 & 672 & 0,23 \\
\hline & ST & 532 & 532 & 170 & 221 & 1550 & 775 & 1528 & \\
\hline & RT & 176 & 176 & 86 & 112 & 778 & 389 & 677 & 0,23 \\
\hline \multicolumn{2}{|c|}{ Utama + Minor Total } & 882 & 882 & 342 & 445 & 3100 & 1550 & 2877 & 0,46 \\
\hline
\end{tabular}

Nilai dari hasil tabel diatas adalah untuk digunkan untuk mencari perhitungan mencari rasio berbelok, derajat kejenuhan dan kapasitas

\subsection{Hasil pengumpulan data sekunder}

\subsubsection{Analisis Simpang Tak Bersinyal}

Data berikutnya yang diperlukan adalah data sekunder yang berupa jumlah penduduk didapatkan dari instansi terkait yaitu Badan Pusat Statistik (BPS) Kabupaten Pandeglang tahun 2018 jumlah penduduk sebesar 1.209.011 jiwa.

Lebar Pendekat dan Tipe Simpang

Lebar pendekat minor adalah rata-rata lebar jalan Majasari - Cibiuk

$\mathrm{W}_{\mathrm{AC}}=\left(\mathrm{W}_{\mathrm{A}}+\mathrm{W}_{\mathrm{C}}\right) / 2$

$\mathrm{W}_{\mathrm{AC}}=\frac{(4,5+4,5)}{2}$

$$
=3 \mathrm{~m}
$$

$\mathrm{W}_{\mathrm{AC}}$ adalah lebar geometrik minor yaitu $\mathrm{A}$ dan $\mathrm{C}$

Lebar pendekat utama adalah rata-rata lebar jalan Serang- Labuan

$\mathrm{W}_{\mathrm{BD}}=\left(\mathrm{W}_{\mathrm{B}}+\mathrm{W}_{\mathrm{D}}\right) / 2$

$\mathrm{W}_{\mathrm{BD}} \quad=\frac{(6,5+6,5)}{2}$

$$
=6,5 \mathrm{~m}
$$

$\mathrm{W}_{\mathrm{BD}}$ adalah lebar geometrik utama $\mathrm{B}$ dan $\mathrm{D}$ 
Lebar pendekat rata-rata dari lebar pendekat jalan minor dan jalan utama, $\mathrm{W}_{1}$

$\mathrm{W}_{1}$ $=\left(\mathrm{W}_{\mathrm{A}}+\mathrm{W}_{\mathrm{C}}+\mathrm{W}_{\mathrm{B}}+\mathrm{W}_{\mathrm{D}}\right) /$ jumlah lengan

$\mathrm{W}_{1}$

$$
\begin{aligned}
& =\frac{(4,5+4,5+6,5+6,5)}{4} \\
& =6 \mathrm{~m}
\end{aligned}
$$

$\mathrm{W}_{1} \quad$ adalah lebar rata rata geometrik mayor dan utama

Tipe Simpang, berdasarkan pemangatan dilapangan bahwa jumlah lajur dari simpang Cikole adalah jalan minor memliki jumlah jalur 2 dan jalan utama memiliki jalur 2, dengan tabel ketentuan mkji didapat tipe simpang dengan 422. Dengan ukuran kota yang telah didapat dari jumlah penduduk diatas maka ukuran kota didapat 1,00 .

Faktor belok kiri $\left(\mathrm{F}_{\mathrm{LT}}\right)$

Untuk pendekat $\mathrm{A}$

$$
\begin{aligned}
\mathrm{FLT} & =0,84+1,61 \times \mathrm{PLT} \\
& =0,84+1,61 \times 0,33 \\
& =1,37
\end{aligned}
$$

$$
\begin{aligned}
& \text { untuk pendekat } \mathrm{C} \\
\text { F }_{\text {LT }} & =0,84+1,61 \times \text { P LT } \\
& =0,84+1,61 \times 0,30 \\
& =1,32
\end{aligned}
$$

Untuk pendekat B

$$
\begin{aligned}
\text { FLT }_{\text {L }} & =0,84+1,61 \times \text { PLT }_{\text {L }} \\
& =0,84+1,61 \times 0,17 \\
& =1,11
\end{aligned}
$$

untuk pendekat $\mathrm{D}$

$$
\begin{aligned}
\text { FLT }_{\text {L }} & =0,84+1,61 \times \text { PLT }_{\text {L }} \\
& =0,84+1,61 \times 0,20 \\
& =1,16
\end{aligned}
$$

Kapasitas

Untuk pendekat $\mathrm{A}$

$\mathrm{C}=\mathrm{C}_{\mathrm{O}} \times \mathrm{F}_{\mathrm{W}} \times \mathrm{F}_{\mathrm{M}} \times \mathrm{F}_{\mathrm{CS}} \times \mathrm{F}_{\mathrm{RSU}} \times \mathrm{F}_{\mathrm{LT}} \times \mathrm{F}_{\mathrm{RT}} \times \mathrm{F}_{\mathrm{MI}}$ $=2900 \times 1.22 \times 1.00 \times 1.00 \times 0.93 \times 1,37 \times 1.00 \times 0,91$

$=4102 \mathrm{smp} / \mathrm{jam}$

untuk pendekat $\mathrm{C}$

$\mathrm{C}=\mathrm{C}_{\mathrm{O}} \times \mathrm{F}_{\mathrm{W}} \times \mathrm{F}_{\mathrm{M}} \times \mathrm{F}_{\mathrm{CS}} \times \mathrm{F}_{\mathrm{RSU}} \times \mathrm{F}_{\mathrm{LT}} \times \mathrm{F}_{\mathrm{RT}} \times \mathrm{F}_{\mathrm{MI}}$

$=2900 \times 1.22 \times 1.00 \times 1.00 \times 0.93 \times 1,32 \times 1.00 \times 0,91$

$=3952 \mathrm{smp} / \mathrm{jam}$

Untuk pendekat $\mathrm{B}$

$$
\begin{aligned}
\mathrm{C} & =\mathrm{C}_{\mathrm{O}} \times \mathrm{F}_{\mathrm{W}} \times \mathrm{F}_{\mathrm{M}} \times \mathrm{F}_{\mathrm{CS}} \times \mathrm{F}_{\mathrm{RSU}} \times \mathrm{F}_{\mathrm{LT}} \times \mathrm{F}_{\mathrm{RT}} \times \mathrm{F}_{\mathrm{MI}} \\
& =2900 \times 1.22 \times 1.00 \times 1.00 \times 0.93 \times 1,11 \times 1.00 \times 0,91 \\
& =3323 \mathrm{smp} / \mathrm{jam}
\end{aligned}
$$

untuk pendekat $\mathrm{D}$

$$
\begin{aligned}
\mathrm{C} & =\mathrm{C}_{\mathrm{O}} \times \mathrm{F}_{\mathrm{W}} \times \mathrm{F}_{\mathrm{M}} \times \mathrm{F}_{\mathrm{CS}} \times \mathrm{F}_{\mathrm{RSU}} \times \mathrm{F}_{\mathrm{LT}} \times \mathrm{F}_{\mathrm{RT}} \times \mathrm{F}_{\mathrm{MI}} \\
& =2900 \times 1.22 \times 1.00 \times 1.00 \times 0.93 \times 1,16 \times 1.00 \times 0,91 \\
& =3473 \mathrm{smp} / \mathrm{jam}
\end{aligned}
$$


Tabel 4 Hasil Perhitungan Kapasitas

\begin{tabular}{|c|c|c|c|c|c|c|c|c|c|}
\hline \multirow[b]{2}{*}{ Pilihan } & Kapasitas & \multicolumn{7}{|c|}{ Faktor korelasi kapasitas $(\mathrm{F})$} & \multirow[b]{2}{*}{$\begin{array}{c}\text { Kapasita } \\
\text { s (C) } \\
\text { smp/jam }\end{array}$} \\
\hline & $\begin{array}{c}\text { Dasar } \\
\text { (Co) smp/ } \\
\text { jam }\end{array}$ & $\begin{array}{c}\text { Lebar } \\
\text { Pendekat } \\
\text { Rata-Rata } \\
\text { Fw }\end{array}$ & $\begin{array}{c}\text { Median } \\
\text { Jalan } \\
\text { Utama } \\
\text { FM } \\
\end{array}$ & $\begin{array}{l}\text { Ukuran } \\
\text { Kota } \\
(\mathrm{FCS})\end{array}$ & $\begin{array}{c}\text { Hambatan } \\
\text { Samping } \\
\text { (FRSU) }\end{array}$ & $\begin{array}{c}\text { Belok } \\
\text { kiri } \\
(\text { FLT })\end{array}$ & $\begin{array}{c}\text { Belok } \\
\text { Kanan } \\
\left(\mathrm{FRT}_{\mathrm{RT}}\right)\end{array}$ & $\begin{array}{c}\text { Rasio Minor } \\
\text { Total (Fm) }\end{array}$ & \\
\hline & 20 & 21 & 22 & 23 & 24 & 25 & 26 & 27 & 28 \\
\hline 1 & 2900 & 1.22 & 1.00 & 1.00 & 0,93 & 1.32 & 1.00 & 0,91 & 4102 \\
\hline 2 & 2900 & 1.22 & 1.00 & 1.00 & 0,93 & 1.32 & 1.00 & 0,91 & 3952 \\
\hline 3 & 2900 & 1.22 & 1.00 & 1.00 & 0,93 & 1.32 & 1.00 & 0,91 & 3323 \\
\hline 4 & 2900 & 1.22 & 1.00 & 1.00 & 0,93 & 1.32 & 1.00 & 0,91 & 3473 \\
\hline
\end{tabular}

Perhitungan Derajat Kejenuhan (DS)

Untuk pendekat A

$\mathrm{DS}=\mathrm{QTOT} / \mathrm{C}$

$$
\begin{aligned}
& =\frac{2877}{4102} \\
& =0,70
\end{aligned}
$$

Untuk pendekat B

$\mathrm{DS}=\mathrm{QTOT} / \mathrm{C}$

$$
\begin{aligned}
& =\frac{2877}{3323} \\
& =0,86
\end{aligned}
$$

Tundaan Simpang

Untuk pendekat A

$$
\begin{aligned}
\mathrm{D} & =\mathrm{DG}+\mathrm{DT}_{1} \\
& =4,12+9,30 \\
& =13,42 \mathrm{detik} / \mathrm{smp}
\end{aligned}
$$

Untuk pendekat $\mathrm{B}$

$$
\begin{aligned}
\mathrm{D} & =\mathrm{DG}+\mathrm{DT}_{1} \\
& =4,05+15,25 \\
& =19,3 \text { detik/smp }
\end{aligned}
$$

untuk pendekat $\mathrm{C}$

$$
\begin{aligned}
\text { DS } & =\text { QTOT/C } \\
& =\frac{2877}{3952} \\
& =0,72
\end{aligned}
$$

untuk pendekat $\mathrm{D}$

$$
\begin{aligned}
\mathrm{DS} & =\mathrm{QTOT} / \mathrm{C} \\
& =\frac{2877}{3473} \\
& =0,82
\end{aligned}
$$

untuk pendekat $\mathrm{C}$

$$
\begin{aligned}
\mathrm{D} & =\mathrm{DG}+\mathrm{DT}_{1} \\
& =4,11+9,81 \\
& =13,92 \text { detik/smp }
\end{aligned}
$$

untuk pendekat $\mathrm{D}$

$$
\begin{aligned}
\mathrm{D} & =\mathrm{DG}+\mathrm{DT}_{1} \\
& =4,07+13,23 \\
& =17,3 \text { detik/smp }
\end{aligned}
$$

Peluang Antrian (QP\%)

Untuk pendekat A

$\mathrm{QP} \%$ batas atas

$$
\begin{aligned}
& =47,71 \times \mathrm{DS}-24,68 \times \mathrm{DS}^{2}+56,47 \times \mathrm{DS}^{3} \\
& =47,71 \times 0,70-24,68 \times 0,70^{2}+56,47 \times 0,70^{3} \\
& =40,67 \%
\end{aligned}
$$

$\mathrm{QP} \%$ batas bawah $=9,02 \times \mathrm{DS}+20,66 \times \mathrm{DS}^{2}+10,49 \times \mathrm{DS}^{3}$

$$
\begin{aligned}
& =9,02 \times 0,70+20,66 \times 0,70^{2}+10,49 \times 0,70^{3} \\
& =20,03 \%
\end{aligned}
$$

untuk pendekat $\mathrm{C}$

$$
\begin{aligned}
\mathrm{QP} \% \text { batas atas } & =47,71 \times \mathrm{DS}-24,68 \times \mathrm{DS}^{2}+56,47 \times \mathrm{DS}^{3} \\
& =47,71 \times 0,72-24,68 \times 0,72^{2}+56,47 \times 0,72^{3} \\
& =42,63 \%
\end{aligned}
$$

$\mathrm{QP} \%$ batas bawah $=9,02 \times \mathrm{DS}+20,66 \times \mathrm{DS}^{2}+10,49 \times \mathrm{DS}^{3}$

$$
\begin{aligned}
& =9,02 \times 0,72+20,66 \times 0,72^{2}+10,49 \times 0,72^{3} \\
& =21,11 \%
\end{aligned}
$$


Untuk pendekat B

$\mathrm{QP} \%$ batas atas

$$
\begin{aligned}
& =47,71 \times \mathrm{DS}-24,68 \times \mathrm{DS}^{2}+56,47 \times \mathrm{DS}^{3} \\
& =47,71 \times 0,86-24,68 \times 0,86^{2}+56,47 \times 0,86^{3} \\
& =58,69 \%
\end{aligned}
$$

$\mathrm{QP} \%$ batas bawah $=9,02 \times \mathrm{DS}+20,66 \times \mathrm{DS}^{2}+10,49 \times \mathrm{DS}^{3}$

$$
\begin{aligned}
& =9,02 \times 0,86+20,66 \times 0,86^{2}+10,49 \times 0,86^{3} \\
& =29,70 \%
\end{aligned}
$$

untuk pendekat $\mathrm{D}$

$$
\begin{aligned}
\mathrm{QP} \% \text { batas atas } & =47,71 \times \mathrm{DS}-24,68 \times \mathrm{DS}^{2}+56,47 \times \mathrm{DS}^{3} \\
& =47,71 \times 0,82-24,68 \times 0,82^{2}+56,47 \times 0,82^{3} \\
& =53,66 \%
\end{aligned}
$$

QP\% batas bawah $=9,02 \times \mathrm{DS}+20,66 \times \mathrm{DS}^{2}+10,49 \times \mathrm{DS}^{3}$

$$
\begin{aligned}
& =9,02 \times 0,82+20,66 \times 0,82^{2}+10,49 \times 0,82^{3} \\
& =27,07 \%
\end{aligned}
$$

Tabel 5 Hasil Perhitungan Perilaku Lalu lintas

\begin{tabular}{|c|c|c|c|c|c|}
\hline \multirow{2}{*}{$\begin{array}{c}\text { Kode } \\
\text { Pendekat }\end{array}$} & \multicolumn{4}{|c|}{ Waktu nyala lampu (detik) } & \multirow{2}{*}{$\begin{array}{l}\text { Siklus } \\
\text { waktu }\end{array}$} \\
\hline & Merah & Kuning & Hijau & All red & \\
\hline A & 84 & 3 & 19 & 1 & \multirow{4}{*}{81} \\
\hline $\mathrm{C}$ & 22 & 3 & 19 & 1 & \\
\hline B & 44 & 3 & 17 & 1 & \\
\hline $\mathrm{D}$ & 65 & 3 & 15 & 1 & \\
\hline
\end{tabular}

\begin{tabular}{cccccccccc}
\hline Pilihan & $\begin{array}{c}\text { Arus Lalu } \\
\text { Lintas (Q) } \\
\text { smp/jam }\end{array}$ & $\begin{array}{c}\text { Dejajat } \\
\text { kenuhan } \\
\text { (DS) }\end{array}$ & $\begin{array}{c}\text { Tundaan } \\
\text { Lalu } \\
\text { Lintas } \\
\text { Simpang }\end{array}$ & $\begin{array}{c}\text { Tundaan } \\
\text { Lalu } \\
\text { Lintas } \\
\text { Utama }\end{array}$ & $\begin{array}{c}\text { Tundaan } \\
\text { Lalu Lintas } \\
\text { Mayor } \\
\text { (DMI) }\end{array}$ & $\begin{array}{c}\text { Tundaan } \\
\text { Geometrik } \\
\text { Simpang } \\
\text { (DG) }\end{array}$ & $\begin{array}{c}\text { Tundaan } \\
\text { Simpang } \\
\text { (D) }\end{array}$ & $\begin{array}{c}\text { Peluang } \\
\text { Antrian } \\
(\text { QP\%) }\end{array}$ & Sasaran \\
\hline 1 & 2877 & 0,7 & 9,3 & 5,50 & 26,74 & 4,12 & 13,42 & $40,67-20,03$ & DS >06 \\
\hline 2 & 2877 & 0,72 & 9,81 & 5,71 & 28,21 & 4,11 & 13,92 & $42,63-21,11$ & DS >06 \\
\hline 3 & 2877 & 0,86 & 15,25 & 7,56 & 43,86 & 4,05 & 19,3 & $58,69-29,70$ & DS >06 \\
\hline 4 & 2877 & 0,82 & 13,23 & 6,95 & 38,05 & 4,07 & 17,3 & $53,66-27,07$ & DS $>06$ \\
\hline
\end{tabular}

3.3. Analisis Simpang Bersinyal

Analisis simpang dapat dihitung berdasarkan Manual Kapasitas Jalan Indonesia (MKJI) 1997 untuk simpang bersinyal. Kondisi eksisting sebelumnya tidak ada lampu APILL pada simpang ini, maka hal pertama yang dilakukan ialah merencanakan waktu sinyal lalu lintas. Perencanaan pemasangan lampu APILL ini dilakukan analisis 4 fase.

Waktu Siklus

Berikut adalah data hasil dari perhitungan untuk mencari siklus sebelum dan sesudah penyesuaian.

Tabel 6 Waktu Siklus

Waktu Hijau

untuk pendekat A dengan $(\mathrm{PRi}=0,27)$

$$
\begin{aligned}
\mathrm{g} & =\left(\mathrm{C}_{\mathrm{ua}}-\mathrm{LTI}\right) \times \mathrm{PR}_{\mathrm{i}} \\
& =(81,7-13) \times 0,27 \\
& =18 \text { detik }
\end{aligned}
$$

untuk pendekat $\mathrm{A}$ dengan $(\mathrm{PRi}=0,27)$

$$
\begin{aligned}
\mathrm{g} & =\left(\mathrm{C}_{\mathrm{ua}}-\mathrm{LTI}\right) \times \mathrm{PR}_{\mathrm{i}} \\
& =(81,7-13) \times 0,27 \\
& =18 \text { detik }
\end{aligned}
$$

untuk pendekat $\mathrm{B}$ dengan $(\mathrm{PRi}=0,25)$

$$
\begin{aligned}
\mathrm{g} & =\left(\mathrm{C}_{\mathrm{ua}}-\mathrm{LTI}\right) \times \mathrm{PR}_{\mathrm{i}} \\
& =(81,7-13) \times 0,25 \\
& =17 \text { detik }
\end{aligned}
$$

untuk pendekat $\mathrm{B}$ dengan $(\mathrm{PRi}=0,25)$

$$
\begin{aligned}
\mathrm{g} & =\left(\mathrm{C}_{\mathrm{ua}}-\mathrm{LTI}\right) \times \mathrm{PR}_{\mathrm{i}} \\
& =(81,7-13) \times 0,19 \\
& =12 \text { detik dibulatkan jadi } 15 \text { detik }
\end{aligned}
$$




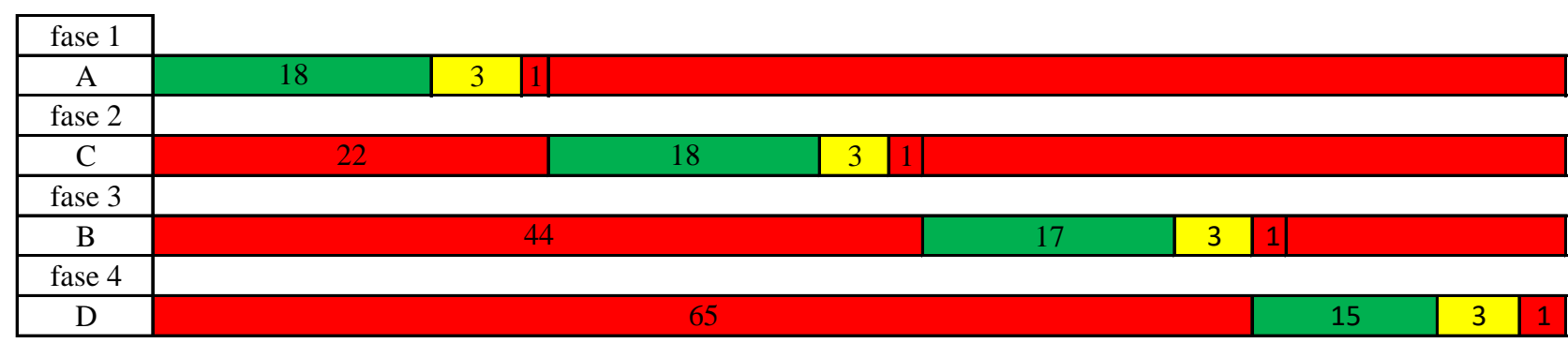

Gambar 3 Diagram Waktu Siklus

Kapasitas

Untuk pendekat A

$$
\begin{aligned}
\mathrm{C} & =\mathrm{S} \times \frac{\mathrm{g}}{\mathrm{c}} \\
& =1717 \times \frac{18}{81} \\
& =381
\end{aligned}
$$

Untuk pendekat $\mathrm{B}$

$$
\begin{aligned}
\mathrm{C} & =\mathrm{S} \times \frac{\mathrm{g}}{\mathrm{c}} \\
& =1717 \times \frac{17}{81} \\
& =818
\end{aligned}
$$

Derajat Kejenuhan Untuk pendekat A

$$
\begin{aligned}
\mathrm{DS} & =\frac{\mathrm{Q}}{\mathrm{C}} \\
& =\frac{343}{381} \\
& =0,90
\end{aligned}
$$

Untuk pendekat $\mathrm{B}$

$$
\begin{aligned}
\mathrm{DS} & =\frac{\mathrm{Q}}{\mathrm{C}} \\
& =\frac{675}{818} \\
& =0,82
\end{aligned}
$$

$$
\begin{array}{ll}
\text { Untuk pendekat } \mathrm{C} \\
\quad=\mathrm{S} \times \frac{\mathrm{g}}{\mathrm{c}} \\
=1717 \times \frac{18}{81} \\
=381
\end{array}
$$

Untuk pendekat $\mathrm{D}$

$$
\begin{aligned}
\mathrm{C} & =\mathrm{S} \times \frac{\mathrm{g}}{\mathrm{c}} \\
& =1717 \times \frac{15}{81} \\
& =770
\end{aligned}
$$

Untuk pendekat $\mathrm{C}$

$$
\begin{aligned}
\mathrm{DS} & =\frac{\mathrm{Q}}{\mathrm{C}} \\
& =\frac{339}{381} \\
& =0,89
\end{aligned}
$$

Untuk pendekat $\mathrm{C}$

$$
\begin{aligned}
\mathrm{DS} & =\frac{\mathrm{Q}}{\mathrm{C}} \\
& =\frac{489}{770} \\
& =0,63
\end{aligned}
$$

Tabel 7 Perhitungan Kapasitas dan Derajat Kejenuhan

\begin{tabular}{ccc}
\hline $\begin{array}{c}\text { Kode } \\
\text { Pendekat }\end{array}$ & $\begin{array}{c}\text { Kapasitas masing-masing } \\
\text { pendekat (C) Sxg/c }\end{array}$ & $\begin{array}{c}\text { Derajat kejenuhan masing- } \\
\text { masing pendekat (DS) }\end{array}$ \\
\hline A & 381 & 0,90 \\
C & 381 & 0,89 \\
B & 818 & 0,82 \\
D & 770 & 0,63 \\
\hline
\end{tabular}

Panjang Antrian

Untuk pendekat $\mathrm{A}$

$$
\begin{aligned}
\mathrm{QL} & =\frac{\mathrm{NQMAX20}}{\mathrm{W}_{\text {masuk }}} \\
& =\frac{16 \times 20}{3} \\
& =71 \mathrm{~m}
\end{aligned}
$$

Untuk pendekat B

$$
\begin{aligned}
\mathrm{QL} & =\frac{\text { NQMAX20 }}{\mathrm{W}_{\text {masuk }}} \\
& =\frac{23 \times 20}{6,5} \\
& =70 \mathrm{~m}
\end{aligned}
$$

Untuk pendekat $\mathrm{C}$

$$
\begin{aligned}
\mathrm{QL} & =\frac{\text { NQMAX20 }}{\mathrm{W}_{\text {masuk }}} \\
& =\frac{12 \times 20}{2,25} \\
& =53 \mathrm{~m}
\end{aligned}
$$

Untuk pendekat D

$$
\begin{aligned}
\mathrm{QL} & =\frac{\text { NQMAX20 }}{\mathrm{W}_{\text {masuk }}} \\
& =\frac{19 \times 20}{3,25} \\
& =58 \mathrm{~m}
\end{aligned}
$$




\subsection{Perbandinngan Hasil Kondisi Eksisting dan Setelah Perencanaan Sinyal}

Dalam proses analisis simpang Cikole untuk kondisi eksisting dan setelah perencanaan fase sinyal terdapat perbedaan hasil angka dari kondisi eksisting dan setelah perencanaan ke fase sinyal. Analisis pada simpang tak bersinyal untuk pendekat A dan C didapat derajat kejenuhan (DS) $=>0,75$, sedangkan pendekat $\mathrm{B}$ dan $\mathrm{D}$ diperoleh derajat kejenuhan $(\mathrm{DS})=0,75>0,80$. Setelah dilakukan analisis ke bersinyal ternyata terjadi perubahan yang cukup besar dengan hasil derajat kejenuhan (DS) $=0,75>0,80$ sehingga belum memenuhi syarat layak simpang bersinyal. Rekapitulasi perbandingan hasil perhitungan kondisi eksisting dan setelah perencanaan sinyal dapat dilihat pada Tabel 8 berikut.

Tabel 8 Perbandingan Kondisi Eksisting dan Perencanaan sinyal

\begin{tabular}{|c|c|c|c|c|c|c|c|c|}
\hline \multirow[b]{2}{*}{ Parameter } & \multicolumn{4}{|c|}{ Eksisting } & \multicolumn{4}{|c|}{ Sinyal } \\
\hline & A & $\mathrm{C}$ & B & $\mathrm{D}$ & A & $\mathrm{C}$ & B & $\mathrm{D}$ \\
\hline Kapasitas (C) & 4102 & 3952 & 3323 & 3473 & 381 & 381 & 818 & 770 \\
\hline Tundaan (D) & 13,42 & 13,92 & 19,3 & 17,3 & 70,44 & 66,76 & 43,11 & 37,03 \\
\hline Peluang Antrian & 40,67 & 42,63 & 58,69 & 53,66 & & & & \\
\hline$(\mathrm{QP} \%)$ & 20,03 & 21,11 & 29,70 & 27,07 & & & & \\
\hline $\begin{array}{l}\text { Panjang Antrian } \\
(\mathrm{QL})\end{array}$ & & & & & 71 & 53 & 70 & 58 \\
\hline $\begin{array}{l}\text { Derajat Kejenuhan } \\
\text { (DS) }\end{array}$ & 0,70 & 0,72 & 0,86 & 0,82 & 0,90 & 0,89 & 0,82 & 0,63 \\
\hline
\end{tabular}

\section{KESIMPULAN}

Adapun beberapa hal yang disimpulkan adalah sebagai berikut.

Berdasarkan pengamatan dan survei arus kendaraan pada simpang Cikole di dapat hasil jam puncak simpang tersebut pada hari Minggu 26 Januari 2020 periode 12:00-13:00 sebesar 4331 kend/hari

Berdasarkan analisis simpang tak bersinyal Cikole pada kondisi eksisting menunjukkan hasil memenuhi persyaratan MKJI 1997,didapat nilai kapasitas terbesar yaitu pendekat A, pendekat, arus lalu lintas sebesar $2887 \mathrm{smp} / \mathrm{jam}$ dan derajat kejenuhan pendekat pendekat B mengahasilkan tundaan simpang pendekat B peluang antrian pendekat $\mathrm{B}$.

Untuk merancang persinyalan simpang Cikole dengan perencanaan pemasangan lampu APILL yang berpedoman pada MKJI 1997, setelah dilakukan analisis menunjukkan nilai pada simpang Cikole dengan derajat kejenuhan $\mathrm{DS}=0,75>0,80$ dimana hasil perencanaan bersinyal pada simpang Cikole dengan nilai derajat kejenuhan pada pendekat $\mathrm{A}$ dengan tundaan yang didapat pendekat $\mathrm{A}$, kapasitas yaitu pendekat $\mathrm{B}$, dengan panjang antrian yang didapat pendekat A.

\section{SARAN}

Dari hasil analisa simpang penulis memberikan beberapa saran untuk penelitian selanjutnya.

Usulan pemasangan APILL untuk menghindari terjadinya konflik dan meminimalisir kecelakaan pada simpang.

Untuk mengatasi permasalahan perencanaan sinyal pada simpang tersebut, sebaik nya dilakukan pelebaran jalan minor maupun jalan utama dan diberi ruang disekitar bahu jalan. Hal ini dimaksudkan untuk mengurangi konflik yang terjadi pada simpang dan dapat menurunkan hambatan samping.

Untuk penelitian selanjutnya diharapakan dapat menganalisis perencanaan simpang menggunakan bundaran.

\section{DAFTAR PUSTAKA}

Amal A.S. (2017). Analisis Kinerja Simpang Empat Bersinyal (Studi Kasus Simpang Empat Taman Dayu Kabupaten Pasuruan), Universitas Muhammadiyah Malang, Malang 
Amtoro A. R. dan Bachnas. (2017). Analisis Kinerja Simpang Tak Bersinyal Empat Lengan (Studi Kasus Jl, Wates Km 5), Universitas Islam Indonesia, Yogyakarta

Departemen Pekerjaan Umum Direktorat Jenderal Bina Marga. (1997). Manual Kapasitas Jalan Indonesia (MKJI), Jakarta

Departemen Permukiman dan Prasarana Wilayah, (2004). Geometri Jalan perkotaan, RSNI T-14-2004, Jakarta Direktorat Jenderal Perhubungan Darat. (1998). Sistem Transportasi Kota, Jakarta

Elisabeth N. R. L. dan Waani J. E. (2015). Analisa Kinerja Simpang Tidak Bersinyal Di Ruas Jalan S.Parman Dan Jalan Di.Panjaitan Kota Manado, Jurnal Sipil Statik Vol.3 No.11

Oglesby, C. H. dan Hicks, R. G. (1982). Teknik Jalan Raya, Edisi ke-4, Jakarta

Peraturan Pemerintah Republik Indonesia Nomor 43 Tahun 1993. (1993). Tentang Prasarana dan Lalu Lintas Jalan Presiden Republik Indonesia. Jakarta

Purwanto. E. (2013). Karakteristik Arus Lalu Lintas, Tegal

Risdiyanto. (2014). Rekayasa dan Manajemen Lalu Lintas: Teori dan Aplikasi, Yogyakarta

Saodang. H. (2010). Kontruksi Jalan Raya, Buku 1, Geometrik Jalan, Bandung

Sugiyono. (2017). Metodologi Penelitian Kuantitatif Kualitatif dan R\&D, Bandung

Suryana. (2010). Metodologi Penelitian Model Praktis Penelitian Kuantitatif dan Kualitatif, Jakarta

Wahyudin. (2015). Analisis Kinerja Simpang Tak Bersinyal Tiga Lengan (Studi Kasus di Jalan Pakuningratan, Yogyakarta), Universitas Muhammadiyah Yogyakarta, Yogyakarta

Wardhana D. R. W. dan Hartantyo S. D. (2016). Analisa Persimpangan Tak Bersinyal Pada Persimpangan Tiga Lengan (Studi Kasus Jalan Veteran - Jalan Ki Sarmidi Mangunsarkoro Lamongan), Jurnal Civilla Vol .1, No 2 